\title{
Antioxidant and antiproliferative properties of strawberry tree tissues
}

\author{
L. Tavares ${ }^{\mathrm{a}}$, S. Fortalezas ${ }^{\mathrm{a}}$, C. Carrilho ${ }^{\mathrm{a}}$, G.J. McDougall ${ }^{\mathrm{b}}$, D. Stewart ${ }^{\mathrm{b}}$, R.B. Ferreira ${ }^{\mathrm{a}, \mathrm{c}}$ \\ and C.N. Santos ${ }^{\mathrm{a}, *}$ \\ ${ }^{a}$ Disease \& Stress Biology Laboratory, Instituto de Tecnologia Química e Biológica, Universidade Nova \\ de Lisboa, Oeiras, Portugal \\ ${ }^{\mathrm{b}}$ Plant Products and Food Quality Programme, Scottish Crop Research Institute, Dundee, Scotland, UK \\ ${ }^{\mathrm{c}}$ Departamento de Botânica e Engenharia Biológica - Instituto Superior de Agronomia, Lisboa, Portugal
}

\begin{abstract}
Strawberry tree (Arbutus unedo) belongs to the Ericaceae family and is endemic to the Mediterranean area. Its fruits are edible and its fruits and leaves are used in folk medicine for diverse purposes. Previous studies have shown that the fruits are rich in flavonoids, responsible for their antioxidant properties and compounds isolated from the entire plant were promising in cancer chemopreventive therapy.

Strawberry tree fruits and leaves extracts enriched in polyphenols, but devoid of organic acids, carotenoids and sugars, were prepared by solid phase extraction (SPE) and tested for their antioxidant activities and their ability to inhibit metalloproteinases: attributes that could be related with initiation and proliferation of cancer cells.

After fractionation by SPE, the apparent polyphenol yield was reduced for both leaf and fruit samples by the elimination of vitamins and organic acids, but the antioxidant and metalloproteinases inhibitory activities were potentiated.

The antioxidant activity and the MMP-9 inhibitory activity of the polyphenol-enriched fractions of $A$. unedo tissues were similar or higher than those of blackberry and green tea, which have been recognized in the literature as highly effective.

The phenolic profile of the fruit was dominated by gallic acid and quercetin derivatives with smaller amounts of proanthocyanidins and anthocyanins. The phenolic profile of the leaves was also dominated by gallic acid derivatives, flavonol derivatives and some tannins but lacked anthocyanins.

The fractions obtained from both strawberry tree tissues seem to be quite promising as antioxidants and antiproliferative agents. Further cell-based assays are underway to study these possible outcomes.
\end{abstract}

Keywords: Arbutus unedo, polyphenols, antioxidant activity, MMP-9, HPLC-MS

\section{Introduction}

There is considerable epidemiological evidence that insufficient intake of fruits and vegetables may predispose the human body to a range of chronic health disorders, including cancer and cardiovascular disease [9]. Phytochemicals, such as polyphenols, present in many fruits and vegetables may participate in disease prevention and this has contributed to the growing interest in identifying components in edible plants responsible for anticancer effects [19].

Polyphenols demonstrate diverse biological activities attributed to their general free radical trapping capacity, or antioxidant activity per se, iron chelation, activation of survival genes, cell signalling pathways and regulation of mitochondrial function $[9,23]$. In cancer, several studies point to the important role of the oxidative stress on the

*Corresponding author: C.N. Santos, Disease \& Stress Biology Laboratory, Instituto de Tecnologia Química e Biológica, Universidade Nova de Lisboa, Av. da República, Apartado 127, 2781-901 Oeiras, Portugal. Tel.: +351 214469651; Fax: +351 214433644; E-mail: csantos@itqb.unl.pt. 
oncogenic stimulation. Various cancer cells have a cellular redox imbalance, i.e, a disruption between endogenous antioxidants and reactive oxygen and nitrogen species (ROS and RNS) balance when compared with normal cells, which could modify permanently the cell biology. This redox imbalance could lead to damage in cellular biomolecules that contribute to induction of mutagenesis and carcinogenesis [37-39]. Free radical damage could influence DNA mutations and altered gene expression, lipid peroxidation due to malondialdehyde (MDA) and 4-hydroxynonenal (HNE) formation [16, 25, 38], and protein oxidation [39].

Cancer cell invasion is a critical point for cancer metastasis. It is generally accepted that remodelling of the extracellular matrix (ECM) is required for cancer cell invasion [41]. The primary response for the degradation of ECM components was demonstrated to be the activation of zinc-dependent matrix metalloproteinases (MMPs) [27]. Although MMPs are expressed in normal tissue in remodelling conditions, such as during embryonic development, wound healing, uterine and mammary involution, cartilage-to-bone transition in ossification, and placenta development, the aberrant expression of various MMPs has been correlated with pathological conditions, such as rheumatoid arthritis, tumour cell invasion and metastasis [12]. Matrix metalloproteinase inhibitors (MMPIs) have been shown to inhibit angiogenesis in various models. However the synthetic inhibitors have demonstrated some disadvantages, such as the lack of selectivity and the secondary effects [24].

Strawberry tree (Arbutus unedo L.; Ericaceae family) is an evergreen shrub, a native Mediterranean species which is also cultivated in other regions of Eastern Europe [3]. Its fruits are spherical, about $2 \mathrm{~cm}$ in diameter, dark red, and tasty only when fully ripen in autumn. A. unedo berries are rarely eaten as fresh fruits but have some importance in local agricultural communities which use them for the production of alcoholic beverages, jams, jellies and marmalades $[2,28]$. The fruits are also used in folk medicine as antiseptics, diuretics and laxatives, while the leaves have long been employed as an astringent, diuretic, urinary anti-septic agent and, more recently, in the therapy of hypertension and diabetes [4]. Recently, Carcache-Blanco and co-workers isolated ten compounds from A. unedo leaves exhibiting chemopreventive action through cyclooxygenase-2 inhibitory activity [6]. This work reinforces $A$. unedo as promising source of antiproliferative agents. Strawberry tree fruit contains several classes of naturally occurring antioxidants such as phenolic compounds (e.g. anthocyanins, gallic acid derivatives, tannins and flavonoids), vitamin C, vitamin E and carotenoids [2, 3, 22, 28, 29], and a high antioxidant capacity [28].

The aim of this work was to assess an in vitro potential of polyphenols from A. unedo fruits and leaves to provide an antiproliferative effect. The extracts prepared were enriched in polyphenols, but devoid of organic acids (vitamin C), carotenoids and sugars. Using this approach, we expect to maximize the activities of the compounds through positive synergisms between the different polyphenols or by eliminating antagonisms, in contrast to the Carcache-Blanco approach that tested pure compounds [6]. Synergistic positive effects are well described between polyphenols [1, $33,35]$. For example, Seeram et al. detected for cranberry extracts [33], after removing sugars and organic acids, a higher antiproliferative activity of polyphenols enriched fraction, when compared against the individual purified phytochemicals.

\section{Material and methodology}

\subsection{Biological material}

Arbutus unedo L. fruits and leaves were collected in November 2007, in Arrábida Natural Park (southern region of Portugal) and frozen. For comparison purposes, the blackberry cv. Apache produced in Fataca experimental field (Odemira, Portugal) and commercial tea leaves (Lipton Green Tea Pure, Lipton) were used as control samples for fruits and leaves, respectively. The samples were freeze-dried, ground and stored at $-80^{\circ} \mathrm{C}$ prior to extraction.

\subsection{Extract preparation}

To each $1 \mathrm{~g}$ of lyophilized powder, $12 \mathrm{~mL}$ of hydroethanolic solvent (50\% (v/v) ethanol/water) was added and the mixture was shaken for $30 \mathrm{~min}$ at room temperature in the dark. The mixture was then centrifuged at $12400 \mathrm{~g}$ for $10 \mathrm{~min}$ at room temperature. The supernatant was filtered through paper filter and then through $0.2 \mu \mathrm{m}$ cellulose acetate membrane filters. The resulting extracts were stored frozen at $-80^{\circ} \mathrm{C}$. 


\subsection{Fractionation by solid phase extraction}

Hydroethanolic extracts were fractionated by Solid Phase Extraction (SPE) using a Giga tubes $2 \mathrm{~g} / 12 \mathrm{~mL}, \mathrm{C} 18$-E units $\left(\right.$ Phenomenex $\left.{ }^{\circledR}\right)$. The columns were pre-washed in $0.5 \%(\mathrm{v} / \mathrm{v})$ glacial acetic acid in acetonitrile and then preequilibrated in $0.5 \%(\mathrm{v} / \mathrm{v})$ glacial acetic acid in water. The extracts were dried under vaccum and ressuspended in $0.5 \%$ $(\mathrm{v} / \mathrm{v})$ glacial acetic acid in water, then they were applied to the columns and unbound material, which contained the free sugars, organic acids or vitamin $\mathrm{C}$, was discarded. The columns were washed with $0.5 \%(\mathrm{v} / \mathrm{v})$ aqueous acetic acid and then polyphenol-enriched bound fractions were eluted with $0.5 \%(\mathrm{v} / \mathrm{v})$ glacial acetic acid in acetonitrile [30, 32].

\subsection{Total phenolic measurement}

Determination of total phenolic compounds was performed by the Folin-Ciocalteau method [34]. Briefly, to each well of a microplate, $235 \mu \mathrm{L}$ water, $5 \mu \mathrm{L}$ sample (or solvent, in the blank), $15 \mu \mathrm{L}$ Folin-Ciocalteau's reagent (Fluka ${ }^{\circledR}$ ) and $45 \mu \mathrm{L}$ saturated $\mathrm{Na}_{2} \mathrm{CO}_{3}$ were added. The microplate was incubated for $30 \mathrm{~min}$ at $40^{\circ} \mathrm{C}$ and the absorbance at $765 \mathrm{~nm}$ measured. Gallic acid was used as the standard and the results were expressed as $\mathrm{mg}$ of gallic acid equivalents (mg GAE).

\subsection{Peroxyl radical scavenging capacity assay}

Peroxyl radical scavenging capacity was determined by the ORAC (Oxygen Radical Absorbance Capacity) method $[5,40]$. Briefly, the reaction mixture contained $150 \mu \mathrm{L}$ of sodium fluorescein $(0.2 \mathrm{nM})$ (Uranine, Fluorescein Sodium Salt ${ }^{\circledR}$ TCI Europe), $25 \mu \mathrm{L}$ sample and $25 \mu \mathrm{L}$ of 2,2'-azobis(2-amidopropane) dihydrochloride (41.4 g. $\left.\mathrm{L}^{-1}\right)$. All solutions are prepared in $75 \mathrm{mM}$ phosphate buffer ( $\mathrm{pH} 7.4$ ). The blank contained $25 \mu \mathrm{L} 75 \mathrm{mM}$ phosphate buffer (pH 7.4) instead of sample, whereas the standards contained $25 \mu \mathrm{L}$ of 10 to $50 \mu \mathrm{M}$ 6-hydroxy-2,5,7,8-tetramethylchroman-2carboxylic acid (Trolox ${ }^{\circledR}$ ) in place of the sample. The fluorescent emission at $515 \mathrm{~nm}$ was then monitored kinetically during $30 \mathrm{~min}$ at $37^{\circ} \mathrm{C}$, after excitation at $493 \mathrm{~nm}$ using a FLx800 Fluorescence Microplate Reader (Biotek). The final results were calculated using the area differences under the fluorescence decay curves between the blank and the sample, and were expressed as $\mathrm{mM}$ Trolox equivalents (mM TE).

\subsection{MMP-9 inhibitory activity assay}

MMP-9 pro-enzyme was activated using 4-aminophenylmercuric acetate (APMA). The enzyme was incubated with $1 \mathrm{mM}$ APMA in $100 \mathrm{mM}$ Tris- $\mathrm{HCl}$ buffer (pH 7.5) containing $100 \mathrm{mM} \mathrm{NaCl}, 10 \mathrm{mM} \mathrm{CaCl}_{2}$ and $0.05 \%(\mathrm{v} / \mathrm{v}$ ) Brij 35 and $2 \%(\mathrm{v} / \mathrm{v}) \mathrm{DMSO}$ for $22 \mathrm{~h}$ at $37^{\circ} \mathrm{C}$ in the dark. Then the reaction was stopped with ice and the active MMP-9 was kept at $4^{\circ} \mathrm{C}$. MMP-9 activity was measured by the direct hydrolysis of MCA-Pro-Leu-Gly-Leu- $\beta$ (Dnpa)-Ala-Ala-Arg-amida substrate [18], which has a fluorescent group 7-metoxicumarin-4-acetil (MCA) and a quenching group 2,4-dinitrofenilamine (Dnpa). Therefore, an increase in fluorescence intensity occurs as a result of substrate hydrolysis, namely the cleavage of peptide Gly-Leu. Before inhibition tests, enzymatic activity using different concentrations of MMP-9 was measured, which revealed a linear relationship between enzyme activity and enzyme concentration (data not shown). The highest concentration was chosen for inhibition assays. The assays were performed on 96 well plates measuring a residual enzymatic activity. The enzyme $(3.2 \mathrm{nM})$ was pre-incubated with $100 \mathrm{mM}$ Tris- $\mathrm{HCl}$ buffer (pH 7.5) containing $100 \mathrm{mM} \mathrm{NaCl}, 10 \mathrm{mM} \mathrm{CaCl}_{2}$ and $0.05 \%$ (v/v) Brij 35 and different concentrations $\left(0-25 \mu \mathrm{g} \mathrm{GAE}\right.$. $\left.\mathrm{mL}^{-1}\right)$ of test fractions at $37^{\circ} \mathrm{C}$ for $30 \mathrm{~min}$. The reaction was initiated by adding the substrate $\left(12 \mu \mathrm{M}\right.$ in the same buffer as the enzyme) in a final volume of $100 \mu \mathrm{L}$. Fluorescence $\left(\lambda_{\text {emission }}=393 \mathrm{~nm}\right.$, $\lambda_{\text {excitation }}=325 \mathrm{~nm}$ ) was measured for $10 \mathrm{~min}$ at room temperature. Results were transformed using a non-linear regression with Origin Pro 6.1 software $\left(\right.$ OriginLab ${ }^{\odot}$, USA) and the $\mathrm{IC}_{50}$ values were determined.

\subsection{HPLC-MS phenolic profile determination}

Phenolic extracts were dried by rotary evaporation, ressuspended in $5 \%(\mathrm{v} / \mathrm{v})$ acetonitrile in water and were analyzed on a LCQ-DECA system controlled by the XCALIBUR software (2.0, ThermoFinnigan). The LCQ-Deca system 
comprised a Surveyor autosampler, pump and photo diode array detector (PDAD) and a Thermo Finnigan mass spectrometer iontrap. The PDA collected spectral data from $200-600 \mathrm{~nm}$ and scanned three discrete channels (at 280, 365 and $510 \mathrm{~nm}$ ). The samples were applied to a C-18 column (Synergi Hydro C18 column with polar end capping, $4.6 \mathrm{~mm} \times 150 \mathrm{~mm}$, Phenomonex Ltd) and eluted over a gradient of 95:5 solvent A:B at time $=0$ min to 60:40 A:B at time $=60 \mathrm{~min}$ at a flow rate of $400 \mu \mathrm{L} / \mathrm{min}$. Solvent A was $0.1 \%(\mathrm{v} / \mathrm{v})$ formic acid in ultra pure water and solvent B $0.1 \%(\mathrm{v} / \mathrm{v})$ formic acid in acetonitrile. The LCQ-Deca LC-MS was fitted with an ESI (electrospray ionization) interface and analyzed the samples in positive and negative-ion mode. Two scan events, full scan analysis in mass range 80-2000 m/z followed by data dependent MS/MS of the most intense ions, were used for compounds detection and identification. The data-dependent MS/MS used collision energies (source voltage) of $45 \%$. The capillary temperature was set at $275^{\circ} \mathrm{C}$ with sheath gas at $60 \mathrm{psi}$ and auxiliary gas at $10 \mathrm{psi}$. Before the analysis, the system was tuned by using known concentrations of cyanidin-3-glucoside (positive mode) and quercetin-3-glucoside (negative mode) in ultrapure water.

\subsection{Statistical analysis}

The results reported in this work are the averages of at least three independent experiments and are represented as the mean \pm SD. Differences among treatments were detected by analysis of variance [31] with Tukey HSD (Honestly Significant Difference) multiple comparison test $(\alpha=0.05)$ using SigmaStat 3.10 (Systat).

\section{Results and discussion}

\subsection{Assessment of bioactivities recovery in polyphenols enriched fractions}

After the hydroethanolic extraction, crude extracts were fractionated by SPE column, to obtain polyphenol-enriched fractions. The crude extracts and enriched fractions were assessed for total phenolic content, antioxidant activity for peroxyl radical and the MMP-9 inhibitory activity (Fig. 1).

After fractionation by the SPE column, strawberry tree fruit and leaf extracts showed a decrease in phenolic content (18\% and 62\% respectively). The decreases observed are probably due to molecules detected by FolinCiocalteu method, such as vitamins or organic acids that are eliminated by the SPE [13]. Indeed, components such

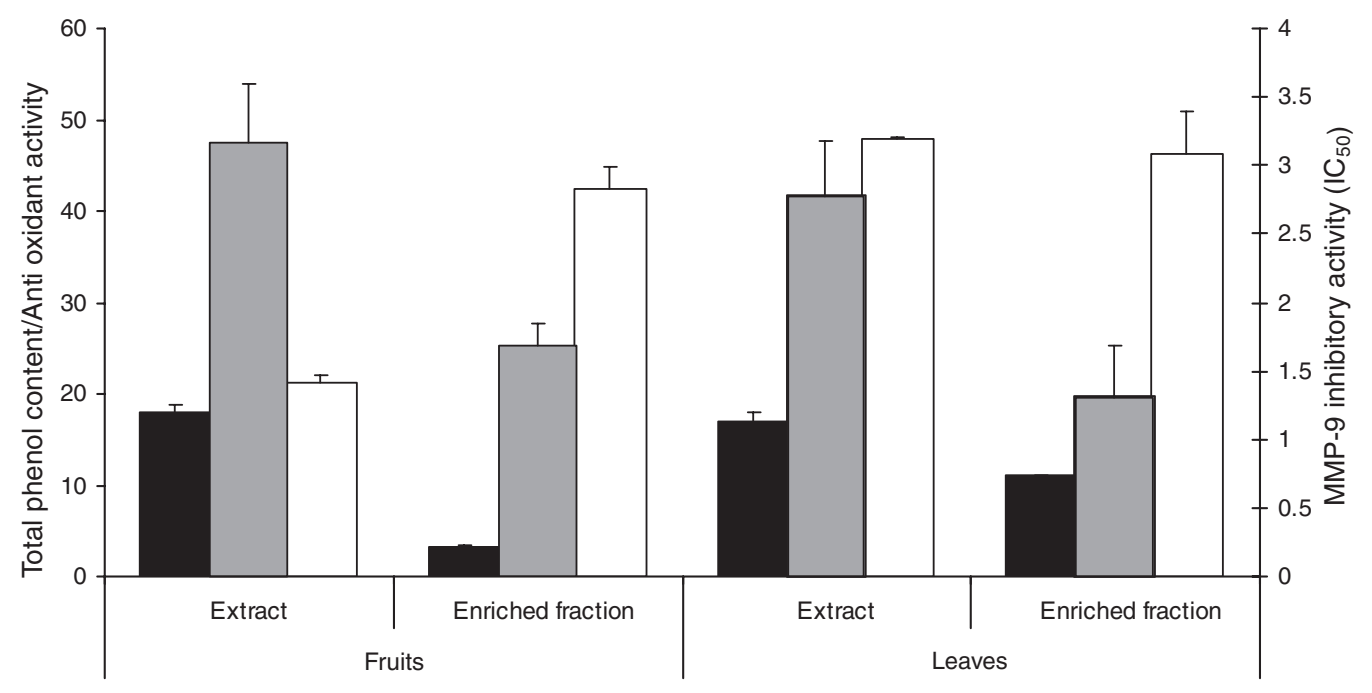

Fig. 1. Comparison of total phenol content, antioxidant capacity and metalloproteinases inhibitory activity between crude extracts and polyphenolenriched fractions obtained from A. unedo fruits and leaves. -total phenol content (mg GAE), $\square-\mathrm{IC}_{50}$ of MMP-9 inhibitory capacity (mg GAE. $\mathrm{mL}^{-1}$ ) and $\square$ antioxidant activity ( $\times 10 \mathrm{mmol}$ TE) for peroxyl radical were determined for crude extracts and polyphenols enriched fractions obtained from A. unedo fruits and leaves. Vertical bars represent \pm SD. 
as niacin, ascorbic acid, $\beta$-carotene, L-malic and quinic acids (detected and quantified in strawberry tree fruits by Alarcão-E-Silva et al. [2] or Ayaz et al. [3]) could account for the apparent loss in "total phenol content" after SPE. The greater decrease in the fruit fraction could be due to the higher contents in vitamins and organic acids in fruits.

The strawberry tree fruit polyphenol-enriched fraction presented an increase of $100 \%$ of antioxidant activity, suggesting that the SPE fractionation eliminated some compounds with antagonistic effects. Strawberry tree leaves had an antioxidant capacity recovery of approximately $100 \%$.

Concerning the MMP-9 inhibitory capacity, the $\mathrm{IC}_{50}$ values for both fractions diminished 50\%, which means that $50 \%$ of the amount of polyphenols is required to produce the same effect as the crude extract.

Therefore, fractionation of strawberry tree tissues using SPE simultaneously eliminated molecules that could exert some antagonistic effects (e.g. in the antioxidant activity) and enriched the phenolic compounds (which diminished the $\mathrm{IC}_{50}$ value for MMP inhibition). However, further fractioning could not be so beneficial, since could eliminate positive synergistic effects, already detected by others [33]. In fact Carcache-Blanco have tested A. unedo isolated compounds and detected lower efficacies (high $\mathrm{IC}_{50}$ ) than their positive controls (13-cis-Retinoic acid and trans-Resveratrol) in chemopreventive assays [6].

\subsection{Antioxidant and MMP-9 inhibitory activities}

The strawberry tree fruit and leaf extracts gave significantly higher antioxidant capacities $(211.66 \pm 22.82 \mathrm{mM} \mathrm{TE}$ and $308.56 \pm 26.74 \mathrm{mM}$ TE, respectively) than blackberry and green tea, respectively (Table 1). The $\mathrm{IC}_{50}$ values of MMP-9 inhibitory activity for both strawberry tree tissues were not significantly different of the amount required for the respective control samples $\left(1.68 \pm 0.38 \mu \mathrm{g}\right.$ GAE. $\mathrm{mL}^{-1}$ for strawberry tree fruits and $1.31 \pm 0.17 \mu \mathrm{g} \mathrm{GAE} . \mathrm{mL}^{-1}$ for leaves) (Table 1).

Control tissues used in this work, blackberry and green tea leaves, are recognized in the literature as highly antioxidants and anti-cancer agents [7, 8, 15, 36, 42-44], Blackberries are a rich source of polyphenols and present a recognized in vitro antioxidant activity (6221 $\mu \mathrm{mol} \mathrm{TE} .100 \mathrm{~g}^{-1}$ determined by ORAC method by Wolfe et al.) [42] as well as a good cellular antioxidant activity detected by a decrease in ROS in cells [42]. These fruits also have shown to inhibit MMP-2 and MMP-9 activities [36]. Moreover, they also could inhibit HT-29 colon tumor cell growth in a concentration-dependent manner [8]. Green tea leaves have been studied for many years and it has been shown their capacity to inhibit carcinogen-induced DNA damage in a number of cell line studies as reviewed by Yang et al. due to their direct radical scavenging and metal chelation $[43,44]$. Tea and tea constituents have been shown to inhibit the development of several cancer in animal models like oral, esophageal, forestomach, stomach, intestinal, colon, skin, liver, bladder, prostate, and breast cancer [7, 15, 44].

In this work results for the $A$. unedo tissues, in comparison with the positive controls, revealed to be promising sources of effective antiproliferative extracts. To confirm these in vitro results, cell based assays should be performed as antiproliferative and intracellular antioxidant tests.

Table 1

Comparison of antioxidant capacity and MMP-9 inhibitory capacity $\left(\mathrm{IC}_{50}\right)$ values for polyphenol-enriched fractions from strawberry tree fruit and leaves with the respective positive controls (blackberry and green tea). Antioxidant capacity was determined by ORAC method and expressed as $\mathrm{mM}$ TE. $\mathrm{IC}_{50}$ values ( $\mu \mathrm{g}$ GAE. $\mathrm{mL}^{-1}$ ) were obtained by OriginPro 6.1 software. The values presented are the mean value of triplicates \pm SD. The values of each tissue were statistically compared with the value of respective control. nd: not significantly different for $p<0.05$; *: significantly different for $p<0.05$; ***: significantly different for $p<0.001$

\begin{tabular}{lllc}
\hline Tissue & Sample & $\begin{array}{c}\text { Antioxidant capacity } \\
(\mathrm{mM} \mathrm{TE})\end{array}$ & $\begin{array}{c}\text { MMP-9 inhibitory capacity } \\
\left(\mathrm{IC}_{50}\right)\left(\mu \mathrm{g} \text { GAE. } \mathrm{mL}^{-1}\right)\end{array}$ \\
\hline Fruits & Blackberry & $118.75 \pm 17.15$ & $1.52 \pm 0.16$ \\
& Strawberry tree & $211.66 \pm 22.82^{* * *}$ & $1.68 \pm 0.38 \mathrm{nd}$ \\
Leaves & Green tea & $135.95 \pm 2.99$ & $1.94 \pm 0.39$ \\
& Strawberry tree & $308.56 \pm 26.74^{*}$ & $1.31 \pm 0.17 \mathrm{nd}$ \\
\hline
\end{tabular}




\subsection{HPLC-MS phenolic profile determination}

To identify the main compounds present in fruits and leaves of strawberry tree, phenolic extracts were analysed by HPLC-ESI-PDA-MS. The compounds were tentatively identified in the bibliography by their PDA and MS fragmentation patterns [28, 29] (Fig. 2; Table 2). The fruits composition is relatively well-known compared to leaves $[28,29]$. The fruits yielded mainly gallic acid derivatives (as glucosides, galloylquinic acid, galloylshikimic acid and gallotannins) but also some proanthocyanidins, quercetin derivatives and ellagic acid derivatives. The anthocyanins are not abundant in these fruits, but were identified in accordance with the bibliography as delphinidin-3-galactoside,
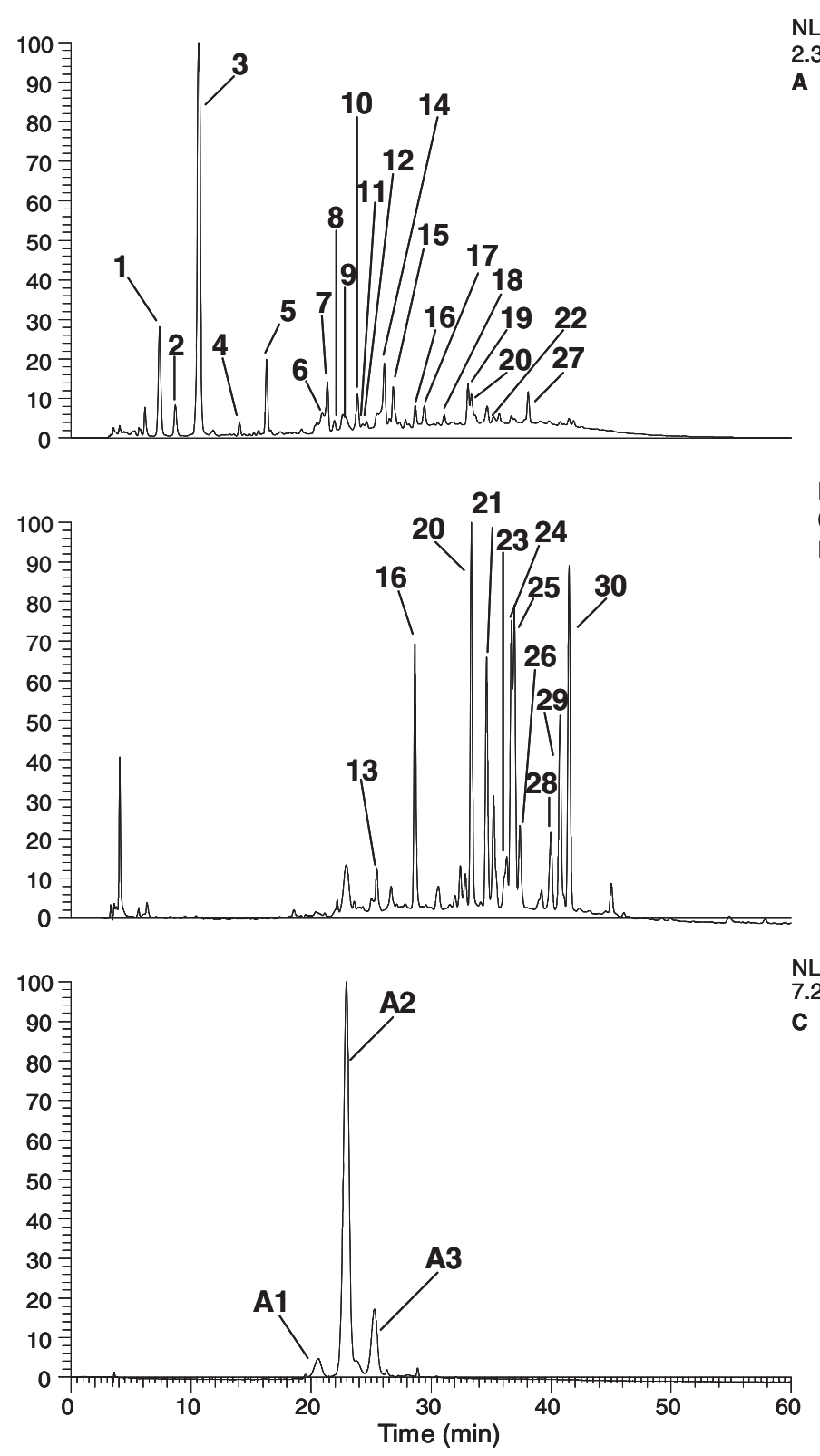

Fig. 2. HPLC phenolic profile assessed for A. unedo fruit extract. The chromatogram in (A) shows the absorbance of peaks at $280 \mathrm{~nm}$, (B) peaks at $365 \mathrm{~nm}$ and $(\mathrm{C})$ peaks at $560 \mathrm{~nm}$. The peaks are numbered and assignments are given in Table 2 for phenols and Table 3 for anthocyanins. 
Table 2

Peaks assignments, retention times and mass spectral data of phenols present in A. unedo fruits extract

\begin{tabular}{|c|c|c|c|c|c|}
\hline Peak no. & RT & PDA & $\mathrm{M} / \mathrm{Z}[\mathrm{M}-\mathrm{H}]$ & MS2 & Putative identity \\
\hline 1 & 7.37 & 280 & 331.1 & $\mathbf{2 7 1 . 0}, 211.1, \mathbf{1 6 9 . 0}$ & Gallic acid glucoside \\
\hline 2 & 8.70 & 265 & 331.1 & 169.0, 125.0 & Galloyl glucoside \\
\hline 3 & 10.64 & 270 & 343.0 & $191.2,169.0$ & 3-O- or 5-O-galloylquinic acid [29] \\
\hline 4 & 14.04 & $255-300$ & 331.1 & 169.1 & $\begin{array}{l}\text { Gallic acid } \\
\text { 4-O-B-D-glucopyranoside or } \\
\text { B-D-Glucogalline [29] }\end{array}$ \\
\hline 5 & 16.29 & $255-300$ & 325.0 & $169.0,125.1$ & Galloyl shikimic acid \\
\hline 6 & 20.93 & 280 & 577.1 & 289.2 & Proanthocyanidin dimer [29] \\
\hline 7 & 21.36 & $270-290$ & $495.0,465.0,343.0,191.2$ & 343.0, 191.0 & Digalloylquinic acid \\
\hline 8 & 21.95 & 295 & $495.0,465.0,343.0,191.2$ & 343.0, 191.0 & Isomer of digalloylquinic acid \\
\hline 9 & 22.66 & 280 & $577.0,423.2,407.2,289.2$ & $425.0,407.2,289.2$ & Procyanidin dimer B2 [28] \\
\hline 10 & 23.86 & 280 & 289.1 & $261.0,175.0$ & Catechin \\
\hline 11 & 24.31 & 320 & $865.1,453.2,325.1$ & 577.1 & Procyanidin trimer \\
\hline 12 & 24.6 & 285 & $541.1,483.1,467.3,321.0,301.2$ & $453.1,301.4,169.2$ & Gallic acid derivative \\
\hline 13 & 25.50 & 280,525 & 477.0, 325.1 & $325.0,169.0$ & Digalloyl shikimic acid \\
\hline 14 & 26.10 & 275 & 477.0, 325.1 & $325.0,169.0$ & Digalloyl shikimic acid \\
\hline 15 & 26.84 & 270 & 633.1, 463.1, 301.2, 275.2 & $463.0,301.1$ & Strictinin ellagitannin \\
\hline 16 & 28.68 & 360 & 463.2, 301.3 & 301.2 & Quercetin-3-glucoside \\
\hline 17 & 29.44 & 275 & $\begin{array}{l}\text { 1109.0, } 972.9,647.0,635.1,588.1 \\
\quad 441.0,301.3\end{array}$ & $783.1,492.8$ & Gallotannin derivative \\
\hline 18 & 31.09 & 280 & 366.2, 186.0 & 204.1, 186.1, 142.0 & Unknown \\
\hline 19 & 33.08 & 275 & 953.0 & $633.0,463.2,301.2$ & Tannin \\
\hline 20 & 33.36 & 360 & $433.1,301.2$ & 301.0 & Quercetin-3-xyloside \\
\hline 21 & 34.67 & $260-355$ & $615.2,463.2,433.1,301.1$ & $463.0,301.1$ & Quercetin hexose galloyl derivative \\
\hline 22 & 35.21 & $260-355$ & $615.2,463.2,433.1,301.1$ & $463.0,301.1$ & Quercetin hexose galloyl derivative \\
\hline 23 & 36.30 & $260-355$ & $615.2,463.2,433.1,301.1$ & $463.0,301.1$ & Quercetin hexose galloyl derivative \\
\hline 24 & 36.69 & 255,370 & 301.2 & $301.2,257.2$ & Ellagic acid \\
\hline 25 & 36.96 & 345 & $463.1,301.2$ & 301.2 & Quercetin 3-galactoside \\
\hline 26 & 37.40 & $275-355$ & 463.1, 301.2 & 301.2 & Quercetin 3-glucoside \\
\hline 27 & 38.09 & 280 & $\begin{array}{l}939.1,769.1,729.0,617.1,544.2 \\
\quad 480.2,469.2\end{array}$ & $769.0,617.2$ & Gallotannin \\
\hline 28 & 39.81 & 355 & $\mathbf{5 9 9 . 0}, 301.0$ & $463.1,301.1$ & Ellagic acid-hexose derivative \\
\hline 29 & 40.75 & 355 & 433.0, 301.1 & 301.1 & Ellagic acid arabinoside/xyloside \\
\hline 30 & 41.49 & 355 & 447.0, 301.1 & 301.1 & Ellagic acid rhamnoside \\
\hline
\end{tabular}

The most abundant ions are shown in bold. Numbers in brackets are references.

cyanidin-3-galactoside, cyanidin-3-glucoside and cyanidin-3-arabinoside [28, 29]. The leaf extracts also yielded gallic acid derivatives common to fruits, (epi)catechin, tannins, myricetin derivatives and kaempferol derivatives. Some of these phytocompounds, such as tannins, quercetin derivatives and catechin gallate have already been described as responsible for anti-hypertensive and anti-aggregant effects using strawberry tree leaf extracts $[20,26]$.

\section{Conclusion}

In this work the polyphenol-enriched fractions of Arbutus unedo fruits and leaves were characterized for antioxidant and MMP-9 inhibitory activity, and the results obtained suggest these tissues as promising sources of agents with pharmacological activities. Many naturally occurring agents have shown chemoprotective potential in a variety of 
Table 3

Peaks assignments, retention times and mass spectral data of anthocyanins present in $A$. unedo fruits extract

\begin{tabular}{lcclll}
\hline Peak no. & RT & PDA & M/Z $[\mathrm{M}+\mathrm{H}]$ & MS2 & Pututative identity \\
\hline A1 & 20.60 & 280,525 & $\mathbf{5 7 9 . 1}, 465.1,303.2$ & 303.2 & Delphinidin-3-galactoside [28] \\
A2 & 22.94 & 280,515 & $\mathbf{4 4 9 . 0 , 2 8 7 . 2}$ & 287.2 & Cyanidin 3-O-glucoside or cyanidin-3-galactoside [28] \\
A3 & 25.28 & 280,515 & $\mathbf{4 1 9 . 1 , 2 8 7 . 2}$ & 287.2 & Cyanidin 3-O-arabinoside [28] \\
\hline
\end{tabular}

The most abundant ions are shown in bold. Numbers in brackets are references.

Table 4

Peaks assignments, retention times and mass spectral data of phenols present in A. unedo leaves extract

\begin{tabular}{|c|c|c|c|c|c|}
\hline Peak No. & RT & PDA & $\mathrm{M} / \mathrm{Z}[\mathrm{M}-\mathrm{H}]$ & MS2 & Putative identity \\
\hline 1 & 9.57 & 280 & $\begin{array}{l}\text { 1111.2, } 899.3,839.3,817.3 \\
\quad 567.3,317.0\end{array}$ & $\begin{array}{l}\mathbf{8 3 9 . 5}, 729.2,676.1,567.2 \\
270.9,160.9,109.2\end{array}$ & Unknown \\
\hline 2 & 10.98 & 280 & 331.2, 271.1, 169.1 & 271.0, 211.1, 169.1 & Gallic acid glucose derivative \\
\hline 3 & 12.80 & 260 & 331.2, 271.2, 169.1 & $271.1,169.1,125.1$ & $\begin{array}{l}\text { B-D-Glucogalline or gallic acid } \\
\text { 4-O-B-D-glucopyranoside }\end{array}$ \\
\hline 4 & 13.54 & 270 & 363.2, 169.2 & 169.1 & $\begin{array}{l}\text { B-D-Glucogalline or gallic acid } \\
\text { 4-O-B-D-glucopyranoside } \\
\text { derivative }\end{array}$ \\
\hline 5 & 14.80 & 275 & 343.1, 191.2 & $191.2,169.1$ & Galloylquinic acid derivative \\
\hline 6 & 20.57 & 275 & 325.2, 169.1, 125.2 & $169.1,125.2$ & Galloylshikimic acid \\
\hline 7 & 26.48 & 275 & 745.1, 577.2, 495.1, 343.1, 289.1 & $593.0,575.1,425.0,407.2$ & Proanthocyanidin derivative \\
\hline 8 & 26.94 & 275 & $423.3,313.2$ & $423.2, \mathbf{3 1 3 . 1}, 169.1$ & Galloyl derivative \\
\hline 9 & 27.92 & 280 & 289.2 & $245.2,231.2,205.2,179.1$ & Catechin \\
\hline 10 & 30.82 & 270 & $\mathbf{4 7 7 . 1}, 325.2,169.2$ & 325.1 & Digalloylshikimic acid derivative \\
\hline 11 & 33.26 & 275 & $\begin{array}{l}\text { 951.1, 933.1, 729.2, 477.1, 301.3 } \\
\quad 273.2\end{array}$ & $\begin{array}{l}914.9,896.9,765.0,613.1 \\
461.1,445.1,301.3\end{array}$ & Tannin \\
\hline 12 & 36.91 & 355 & $\begin{array}{l}1105.0,1085.0,953.2,935.2,785.1 \\
633.2,479.2,316.2,301.3\end{array}$ & $\begin{array}{l}909.1,801.0,633.1,463.2, \\
\quad 301.3\end{array}$ & Tannin \\
\hline 13 & 38.57 & 280 & $629.0,477.1,325.2$ & 325.1 & Galloylshikimic acid derivative \\
\hline 14 & 41.26 & 360 & 463.2, $449.2,316.2$ & 316.2 & Myricetin-3-rhamnose \\
\hline 15 & 43.04 & 280,355 & $\begin{array}{l}\text { 939.2, 769.2, 617.2, 469.3, 301.3 } \\
\quad 169.1\end{array}$ & 787.1, 769.1, 617.2, 601.2 & Gallotannin \\
\hline 16 & 46.51 & 255,350 & $447.2,300.2$ & 301.1 & Quercetin 3-rhamnoside \\
\hline 17 & 50.25 & 350 & $583.2, \mathbf{4 1 7 . 2}, 300.2,284.2$ & $417.2,327.1, \mathbf{2 8 4 . 1}, 255.3$ & $\begin{array}{l}\text { Kaempferol derivative } \\
\text { (Arabinoside/Xyloside) }\end{array}$ \\
\hline 18 & 51.17 & 265,340 & $476.8, \mathbf{4 3 1 . 2}, 285.2,227.3$ & 285.2 & Kaempferol derivative (Rhamnoside) \\
\hline 19 & 38.03 & 355 & 479.2, 317.2 & 317.1 & Myricetin-Hexoside \\
\hline 20 & 42.56 & 350 & $463.0,300.1$ & 301.1 & Quercetin-Hexoside \\
\hline
\end{tabular}

The most abundant ions are shown in bold.

bioassay systems and animal models. Phenolic compounds are reported to have antioxidant, antimutagenic and anticarcinogenic activity and are expected to reduce the risk of disease and to bring health benefits with daily intake [11].

Gallic acid derivatives dominate the profile of both fruits and leaves of Arbutus unedo. Gallic acid is an intermediate component of plant metabolism and, together with its analogs, has been associated with a wide variety of biological actions, including: antioxidant, antifungal, antimalarial, and antiherpetic action [10, 14, 17]. However, the main interest in gallic acid and its derivatives is related to its antitumoral activity, showing selective cytotoxicity toward a variety of tumor cells, more cytotoxic for tumor cells than for non-tumor cells [21]. Nevertheless, in studies using 
pure coumpounds, synergistic effects may be lost in determining anti-proliferative effects. In this study, the use of polyphenols-enriched fraction, devoid of ascorbic acid and carotenoids, allows interactions between polyphenols and the detected bioactivity could be directly associated to them and their interactions. Fruits and leaves polyphenolsenriched fractions presented $\mathrm{IC}_{50}$ values similar to the ones obtained for positive control tissues with recognized activity as anti-cancer and antioxidant agents. Therefore, it is important to confirm the potential of these enriched fractions as multitarget medicines with antiproliferative efficacy, using cell based assays such as proliferation and intracellular antioxidant tests.

\section{Acknowledgements}

To FCT for financial support of Claudia Santos (SRFH/BPD/26562/2006) and Lucélia Tavares (SFRH/BD/37382/ 2007) and to Cost Office 863.

\section{References}

[1] N. Aftab and A. Vieira, Antioxidant activities of curcumin and combinations of this curcuminoid with other phytochemicals, Phytotherapy Research (2009), in press.

[2] M.L.C.M.M. Alarcao-E-Silva, A.E.B. Leitao, H.G. Azinheira and M.C.A. Leitao, The Arbutus berry: Studies on its color and chemical characteristics at two mature stages, Journal of Food Composition and Analysis 14 (2001), 27-35.

[3] F.A. Ayaz, M. Kucukislamoglu and M. Reunanen, Sugar, non-volatile and phenolic acids composition of strawberry tree (Arbutus unedo L. var ellipsoidea) fruits, Journal of Food Composition and Analysis 13 (2000), 171-177.

[4] M. Bnouham, F.Z. Merhfour, A. Legssyer, H. Mekhfi, S. Maallem and A. Ziyyat, Antihyperglycemic activity of Arbutus unedo, Ammoides pusilla and Thymelaea hirsuta, Pharmazie 62 (2007), 630-932.

[5] G. Cao, H.M. Alessio and R.G. Cutler, Oxygen-radical absorbance capacity assay for antioxidants, Free Radical Biology \& Medicine 14 (1993), 303-311.

[6] E.J. Carcache-Blanco, M. Cuendet, E.J. Park, B.N. Su, J.F. Rivero-Cruz, N.R. Farnsworth and A.D. Kinghorn, Potential cancer chemopreventive agents from Arbutus unedo, Natural Product Research 20 (2006), 327-334.

[7] G.J. Dai, H.Y. Jin, Y.J. Ding, J.G. Xia, X.F. Liu, F. Liu, X.Z. Tan and J.X. Geng, Anticancer effects of tea polyphenols on colorectal cancer with microsatellite instability in nude mice, Zhong Xi Yi Jie He Xue Bao 6 (2008), 1263-1266.

[8] J. Dai, J.D. Patel and R.J. Mumper, Characterization of blackberry extract and its antiproliferative and anti-inflammatory properties, Journal of Medicinal Food 10 (2007), 258-265.

[9] S. Dore, Unique properties of polyphenol stilbenes in the brain: more than direct antioxidant actions; gene/protein regulatory activity, Neurosignals 14 (2005), 61-70.

[10] S.M. Fiuza, C. Gomes, L.J. Teixeira, M.T. Girao da Cruz, M.N. Cordeiro, N. Milhazes, F. Borges and M.P. Marques, Phenolic acid derivatives with potential anticancer properties-a structure-activity relationship study, Part 1: methyl, propyl and octyl esters of caffeic and gallic acids, Bioorganic \& Medicinal Chemistry 12 (2004), 3581-3589.

[11] G. Galati and P.J. O'Brien, Potential toxicity of flavonoids and other dietary phenolics: significance for their chemopreventive and anticancer properties, Free Radical Biology \& Medicine 37 (2004), 287-303.

[12] Z.S. Galis and J.J. Khatri, Matrix metalloproteinases in vascular remodeling and atherogenesis: the good, the bad and the ugly, Circulation Research 90 (2002), 251-262.

[13] S. George, P. Brat, P. Alter and M.J. Amiot, rapid determination of polyphenols and vitamin C in plant-derived products, Journal of Agricultural and Food Chemistry 53 (2005), 1370-1373.

[14] P. Grundhofer, R. Niemetz, G. Schilling and G.G. Gross, Biosynthesis and subcellular distribution of hydrolyzable tannins, Phytochemistry 57 (2001), 915-927.

[15] D.H. Han, J.H. Jeong and J.H. Kim, Anti-proliferative and apoptosis induction activity of green tea polyphenols on human promyelocytic leukemia HL-60 cells, Anticancer Research 29 (2009), 1417-1421.

[16] S.P. Hehner, R. Breitkreutz, G. Shubinsky, H. Unsoeld, K. Schulze-Osthoff, M.L. Schmitz and W. Droge, Enhancement of T cell receptor signaling by a mild oxidative shift in the intracellular thiol pool, Journal of Immunology 165 (2000), 4319-4328.

[17] E. Klein and N. Weber, In vitro test for the effectiveness of antioxidants as inhibitors of thiyl radical-induced reactions with unsaturated fatty acids, Journal of Agricultural and Food Chemistry 49 (2001), 1224-1227.

[18] C.G. Knight, F. Willenbrock and G. Murphy, A novel coumarin-labelled peptide for sensitive continuous assays of the matrix metalloproteinases, FEBS Letters 296 (1992), 263-266. 
[19] P.M. Kris-Etherton, K.D. Hecker, A. Bonanome, S.M. Coval, A.E. Binkoski, K.F. Hilpert, A.E. Griel and T.D. Etherton, Bioactive compounds in foods: their role in the prevention of cardiovascular disease and cancer, American Journal of Medicine 113(Suppl 9B) (2002), 71S-88S.

[20] A. Legssyer, A. Ziyyat, H. Mekh, M. Bnouham, C. Herrenknecht, V. Roumy, C. Fourneau, A. Laurens, J. Hoerter and R. Fischmeister, Tannins and catechin gallate mediate the vasorelaxant effect of Arbutus unedo on the rat isolated aorta, Phytotherapy Research 18 (2004), 889-894.

[21] C. Locatelli, P.C. Leal, R.A. Yunes, R.J. Nunes and T.B. Creczynski-Pasa, Gallic acid ester derivatives induce apoptosis and cell adhesion inhibition in melanoma cells: The relationship between free radical generation, glutathione depletion and cell death, Chemico-Biological Interactions 181 (2009), 175-184.

[22] Z. Males, M. Plazibat, V.B. Vundac and I. Zuntar, Qualitative and quantitative analysis of flavonoids of the strawberry tree-Arbutus unedo L. (Ericaceae), Acta Pharmaceutica 56 (2006), 245-250.

[23] S. Mandel and M.B. Youdim, Catechin polyphenols: neurodegeneration and neuroprotection in neurodegenerative diseases, Free Radical Biology \& Medicine 37 (2004), 304-317.

[24] F. Mannello, Natural bio-drugs as matrix metalloproteinase inhibitors: new perspectives on the horizon? Recent Patents on Anticancer Drug Discovery 1 (2006), 91-103.

[25] L.J. Marnett, Lipid peroxidation-DNA damage by malondialdehyde, Mutation Research 424 (1999), 83-95.

[26] H. Mekhfi, M. ElHaouari, M. Bnouham, M. Aziz, A. Ziyyat and A. Legssyer, Effects of extracts and tannins from Arbutus unedo leaves on rat platelet aggregation, Phytotherapy Research 20 (2006), 135-139.

[27] H. Nagase and K. Brew, Designing TIMP (tissue inhibitor of metalloproteinases) variants that are selective metalloproteinase inhibitors, Biochemical Society Symposia (2003), 201-212.

[28] K. Pallauf, J.C. Rivas-Gonzalo, M.D. del Castillo, M.P. Cano and S. de Pascual-Teresa, Characterization of the antioxidant composition of strawberry tree (Arbutus unedo L.) fruits, Journal of Food Composition and Analysis 21 (2008), 273-281.

[29] A.M. Pawlowska, M. De Leo and A. Braca, Phenolics of Arbutus unedo L. (Ericaceae) fruits: identification of anthocyanins and gallic acid derivatives, Journal of Agricultural and Food Chemistry 54 (2006), 10234-10238.

[30] Phenomenex, SPE reference Manual \& Users Guide, 2000.

[31] M. Popova, V. Bankova, D. Butovska, V. Petkov, B. Nikolova-Damyanova, A.G. Sabatini, G.L. Marcazzan and S. Bogdanov, Validated methods for the quantification of biologically active constituents of poplar-type propolis, Phytochemical Analysis 15 (2004), 235-240.

[32] H.A. Ross, G.J. McDougall and D. Stewart, Antiproliferative activity is predominantly associated with ellagitannins in raspberry extracts, Phytochemistry 68 (2007), 218-228.

[33] N.P. Seeram, L.S. Adams, M.L. Hardy and D. Heber, Total cranberry extract versus its phytochemical constituents: antiproliferative and synergistic effects against human tumor cell lines, Journal of Agricultural and Food Chemistry 52 (2004), 2512-2517.

[34] V.L. Singleton and J.A. Rossi, Colorimetry of total phenolics with phosphomolybdic-phosphotungstic acid reagents, American Journal of Enology and Viticulture 16 (1965), 144-158.

[35] M. Suganuma, S. Okabe, Y. Kai, N. Sueoka, E. Sueoka and H. Fujiki, Synergistic effects of (-)-epigallocatechin gallate with (-)-epicatechin, sulindac, or tamoxifen on cancer-preventive activity in the human lung cancercell line PC-9, Cancer Research 59 (1999), 44-47.

[36] P. Tate, J. God, R. Bibb, Q. Lu and L.L. Larcom, Inhibition of metalloproteinase activity by fruit extracts, Cancer Letters 212 (2004), $153-158$.

[37] M. Valko, M. Izakovic, M. Mazur, C.J. Rhodes and J. Telser, Role of oxygen radicals in DNA damage and cancer incidence, Molecular and Cellular Biochemistry 266 (2004), 37-56.

[38] M. Valko, H. Morris, M. Mazur, P. Rapta and R.F. Bilton, Oxygen free radical generating mechanisms in the colon: do the semiquinones of vitamin K play a role in the aetiology of colon cancer? Biochimica et Biophysica Acta 1527 (2001), 161-166.

[39] M. Valko, C.J. Rhodes, J. Moncol, M. Izakovic and M. Mazur, Free radicals, metals and antioxidants in oxidative stress-induced cancer, Chemico-Biological Interactions 160 (2006), 1-40.

[40] S.Y. Wang and H.S. Lin, Antioxidant activity in fruits and leaves of blackberry, raspberry and strawberry varies with cultivar and developmental stage, Journal of Agricultural and Food Chemistry 48 (2000), 140-146.

[41] J. Westermarck and V.M. Kahari, Regulation of matrix metalloproteinase expression in tumor invasion, FASEB Journal 13 (1999), 781-792.

[42] K.L. Wolfe, X. Kang, X. He, M. Dong, Q. Zhang and R.H. Liu, Cellular antioxidant activity of common fruits, Journal of Agricultural and Food Chemistry 56 (2008), 8418-8426.

[43] C.S. Yang, J. Hong, Z. Hou and S. Sang, Green tea polyphenols: antioxidative and prooxidative effects, Journal of Nutrition 134 (2004), 3181S.

[44] C.S. Yang, J.D. Lambert and S. Sang, Antioxidative and anti-carcinogenic activities of tea polyphenols, Archives of Toxicology 83 (2009), $11-21$. 